DOI: 10.17805/trudy.2016.3.4

\title{
ВЛИЯНИЕ СРЕДСТВ МАССОВОЙ КОММУНИКАЦИИ НА РАЗВИТИЕ СОЦИАЛЬНОЙ МОДЕРНИЗАЦИИ В РОССИИ
}

\author{
Е. М. Акимова \\ (Московский гуманитарный университет)
}

Аннотация: В статье рассматриваются проблемы социальной модернизации России. Особое внимание уделяется анализу российского менталитета, объективной необходимости его трансформации, раскрывается первостепенное значение средств массовой коммуникации в решении этих актуальных задач.

Ключевые слова: модернизация; социальная модернизация; средства массовой коммуникации; русский менталитет; методика Хофстеда

\section{THE INFLUENCE OF MASS COMMUNICATION ON THE SOCIAL MODERNIZATION IN RUSSIA}

\author{
E. M. Akimova \\ (Moscow University for the Humanities)
}

\begin{abstract}
The article deals with the issues of social modernization in Russian Federation, with a particular focus on analyzing Russian mentality and the objective necessity of its transformation. The paramount role in solving these important tasks belongs to mass media, but it is achievable only if a journalist has mastered sociological thinking and can use scientific knowledge and scientific research methods in the analysis of social facts and social processes. In addition, journalists have to present information to the mass audience in a way which adequately reflects the social reality. All of these points are important for social integration, humanization, intellectualization and true democratization of society. They are also paramount for the development of patriotism.

Keywords: modernization; social modernization; mass media; Russian mentality; Hofstede method
\end{abstract}

Модернизация как социальное явление представляет собой сложный и длительный процесс системных социальных изменений во всех сферах общественной жизни, сопровождающийся изменением культурных образцов и стереотипов, уровней организации, структурными и функциональными преобразованиями во всех сферах общества. Она предполагает политические, экономические, социокультурные, социально-психологические, семейно-бытовые изменения в обществе, а также существенные изменения в мировоззрении и общественном сознании.

Модернизация является тем механизмом, который позволяет тради- 
ционным обществам перейти в разряд обществ индустриальных, а индустриальным обществам - в современные информационные. Модернизация, обеспечивающая переход к современному обществу стран так называемого «третьего мира» осуществлялась посредством «ликвидации недоразвитости» по западному типу. Основной путь, который здесь использовался - это индустриализация. Крупномасштабная индустриализация, проведенная в Советском Союзе, по многим параметрам приблизила российское общество к современному.

Однако Россия и в настоящее время остается и развитой индустриальной страной, и, вместе с тем, традиционным обществом с его особенностями, достоинствами и недостатками, что в определенной мере затрудняет ее трансформацию в современное общество.

Формирование современного информационного общества - не единовременный акт, а сложный, длительный процесс, на протяжении которого сочетаются старое и новое, традиции и инновации. Формирование и развитие информационного общества требуют многих кардинальных технических, экономических, политических, информационных и других изменений и преобразований, в том числе и социальной модернизации (Ильинский, 2006).

Важным фактором и составной частью социальной модернизации является менталитет. Он является базовой основой социальной модернизации в условиях формирующегося нового информационного общества в современной российской действительности. Под менталитетом обычно понимается особый духовный склад ума, образ мышления, мировосприятия, мироощущения, духовную настроенность, самобытность и самодостаточность, обобщенные представления о реальности, устойчивые интеллектуальные и эмоциональные особенности, присущие индивиду или социальной группе, обществу, а также особенности индивидуального и общественного сознания, глубинные этно-национальные особенности народов и культуры. Самобытность, неповторимость и оригинальность национального характера, национального менталитета отражается в понятиях русского, американского, китайского и т. д. менталитетов.

Менталитет в конечном счете определяет тип мышления, образ мыслей, приоритетов, оценок и форм поведения человека в рамках данной общности, общества. Менталитет может быть рассмотрен как некий мировоззренческий стандарт, который устойчив и изменяется очень медленно в течение длительного времени, при этом сохраняя свое «ментальное ядро» практически неизменным. Вместе с тем ментальность предстает как характеристика глубинных пластов психики, формирующаяся в недрах культуры и особенностях социализации, проявляющаяся в индивидуальном и коллективном сознании, национальном характере. 
Менталитет, ментальность очень устойчивы, но и они подвержены изменениям во времени и пространстве. Только с учетом особенностей русского менталитета можно решить задачу первостепенной важности: разработать программу социальных преобразований в России в наибольшей степени удовлетворяющую потребностям всех социальных групп. А пока, считает М. К. Горшков, модернизационные сценарии будущего России рассматриваются и властными структурами и рядовыми согражданами сквозь призму собственных предпочтений и интересов, чему в немалой степени способствует идеологическая неопределенность провозглашенного курса на модернизацию, оставляющая различным группам и слоям общества возможность примерять этот курс «на себя», свои взгляды и ценности (Горшков, 2010). Достижение этой цели требует изучения русского менталитета.

Общепризнанной, проверенной методикой анализа ментальных характеристик различных этнических групп является методика, разработанная Г. Хофстедом, базовые показатели которой - «Индивидуализм», «Дистанция власти», «Маскулинность», «Избегание неопределенности» (Hofstede, 1980, 2001).

Каждый из показателей Г. Хофстеда основан на тестировании четырех ценностей. Эти ценности тесно взаимосвязаны друг с другом: рост/снижение важности для респондентов одной из ценностей чаще всего приводит к аналогичным изменениям в отношении и ко всем другим ценностям этой группы.

Проведенные социологические исследования по данной методике в России дали следующую картину (таб. 1).

Таблица 1. Показатели культурной специфики россиян, в \% Table 1. Cultural specificity of Russians, \% by indicator

\begin{tabular}{|c|c|c|c|c|}
\hline Ценности & $\begin{array}{c}\text { Дистанция } \\
\text { власти }\end{array}$ & $\begin{array}{c}\text { Индивидуа- } \\
\text { лизм }\end{array}$ & Маскулинность & $\begin{array}{c}\text { Избегание } \\
\text { неопределен- } \\
\text { ности }\end{array}$ \\
\hline Показатели & 28 & 61 & 36 & 91 \\
\hline
\end{tabular}

Показатель «Индивидуализма» у современных россиян равен 61 единице. Он тоже обладает в России своей спецификой. Вместо того, чтобы проявлять единообразие в восприятии ценностей данного культурного блока, россияне демонстрируют сочетание разнонаправленных ценностных установок. Проведенные социологические исследования показывают, что они проявляют индивидуалистические качества в тех случаях, когда дело касается их отношения к группе: свою личную жизнь они ставят на первое место, а при выборе работы думают не о благе общества, а о возможностях самореализации. Однако в тех случаях, когда речь заходит об 
отношении группы к ним, россияне неожиданно превращаются в коллективистов. Таким образом, можно сделать вывод, что россияне сохранили с советских (если не с еще более ранних) времен уверенность, что группа должна оказывать им поддержку и заботиться об их нуждах, но при этом уже не очень склонны жертвовать своими интересами ради этой группы (Аникин, 2009).

«Дистанция власти». Один из главных институтов, которые определяют тип общества, - это социальное неравенство. Отношение к распределению неравенства в обществе определяет и стили взаимодействия между теми, кто обладает властью, и теми, кто ей подчиняется. В обществах с небольшим неравенством (низкой «Дистанцией власти») предпочитают консультативный стиль взаимоотношений: руководитель и подчиненный независимы друг от друга и вместе принимают ответственные решения. Это типично для стран Запада. В обществах с большим неравенством (высокой «Дистанцией власти») предпочтение отдается авторитарному и патерналистскому стилю руководства: наблюдается высокая степень зависимости нижестоящих от вышестоящих и, следовательно, решение принимается исходя в первую очередь из мнения вышестоящих. Такие «правила игры» типичны для стран Востока.

Показатель «Дистанции власти» в России равен 28. За очень низким российским показателем «Дистанции власти» стоят во многом противоречивые установки. С одной стороны, Россию считают страной с авторитарными традициями, между тем данные социологических опросов характеризуют нашу страну как вполне демократическую по своей ментальности. В России нет ни признания равноправия, ни почитания власти. Одна сторона делает вид, что проводит политику, основанную на мнении большинства, а другая делает вид, что выполняет спущенные им «сверху» решения (Вознесенская, 2008).

«Маскулинность». К ценностям маскулинных обществ относят стремление к максимизации дохода и признания, продвижению вперед (например, карьерный рост), борьбе (конкуренция). Противоположных ценностей придерживаются люди в феминных обществах - поддержание дружеских отношений, кооперация, комфорт, безопасность.

Отметим, что одними из главных черт россиян являются их гостеприимство, доброта и отзывчивость. Все эти качества - основа феминной ментальности, а сама «женственность» русской души не единожды становилась темой дебатов среди русских философов.

«Избегание неопределенности». Погодные условия, природные катаклизмы, непостоянство человеческих чувств, желаний, предпочтений и ощущений, наконец, сама жизнь человека - все это было и остается для людей источниками неопределенности. Чтобы хотя бы частично избежать 
неопределенности, люди с давних пор используют технологии, правила и законы, а также религию.

Культуры с повышенной степенью беспокойности - это, как правило, культуры высокоэмоциональные. При этом представители такого рода культуры характеризуются высоким уровнем потребления алкоголя, который обладает расслабляющим действием и помогает снять стресс, вызванный постоянным беспокойством и напряжением. Другим способом регуляции культурного невротизма является минимизация беспокойства посредством введения формальных и неформальных правил поведения, Страны, предпочитающие большое количество правил, относятся к культуре с высоким «Избеганием неопределенности». Россия относится к группе стран с весьма высоким «Избеганием неопределенности» (этот показатель равен 91).

Специфика русского менталитета проявляется в том, что для России типичны смещенные к странам Запада показатели «Дистанции власти» и «Индивидуализма». При этом у России наблюдаются очень высокое «Избегание неопределенности», нехарактерное даже для большинства восточных стран, и пониженный показатель «Маскулинности», который отличает ее и от стран Запада, и от большинства стран Востока.

Разрабатывая сценарий социальной модернизации, целесообразно максимально учитывать особенности русского менталитета, его противоречивость, потребность в справедливости, уважении и другие черты.

Другой сложной и актуальной проблемой социальной модернизации в России, которая может быть решена только с учетом специфики русской ментальности, является мотивация участия населения в модернизационном процессе. Прояснив общественный и личностный смысл модернизации, человек может включиться в этот процесс осознанно.

Важнейшая роль социальной модернизации России принадлежит СМИ и СМК. Именно они эффективно воздействуют на образ мышления массовой аудитории, ее мировосприятие, представление о реальности, формируют особенности индивидуального и общественного сознания, то есть оказывают решающее воздействие на менталитет, трансформация которого в нашей стране имеет первостепенное значение.

«СМИ способны служить различным политическим целям и идеалам. Они могут просвещать людей, развивать в них чувство собственного достоинства, стремление к свободе и социальной справедливости, способствовать компетентному участию в политических процессах, обогащать личность, но могут и духовно порабощать, дезинформировать и запугивать, разжигать массовую ненависть, сеять недоверие и страх» (Коновченко, Киселев, 2004: 484).

Еще большими возможностями влияния на население обладают СМК. 
«Уровень сознания массами своего положения и своих претензий зависит от идей, имеющих хождение в обществе. Их распространение после изобретения письменности легло на книги и средства массовой информации, а впоследствии - на новейшие средства массовой коммуникации». (там же: 108).

По мнению известного испанского мыслителя М. Кастельса, в информационную эпоху гигантски возросла зависимость общества от СМК и СМИ. В итоге, считает Кастельс, имеет место диверсификация, персонификация и виртуализация аудитории, и в данной реальности «не мы контролируем их (СМИ), а они - нас» (Кастельс, 2000: 40).

Следует подчеркнуть, что возрастание значимости информационнопсихологического воздействия на человека, глобализация этого процесса, разработка все более эффективных информационных технологий превратило СМИ и СМК в доминирующее средство влияния на личность и население в целом. С учетом высочайшей значимости влияния СМИ и СМК на аудиторию становится ясной та ответственность, которую несет журналист за свою работу. От его профессионализма, широты и глубины образования, личностных качеств зависит, какую информацию получит или не получит массовая аудитория - правдивую или искаженную, полную или нет, а главное субъективную или отражающую объективную реальность такой, какая она есть.

Чтобы сеять «разумное, вечное, доброе», у журналиста должна быть четкая социальная позиция, сформировано социологическое мышление, осознание его роли и самого себя в информационно-коммуникативном процессе. Только тогда возможно гражданское служение обществу, творческая самореализация, высокий профессионализм и постижение сущности происходящего. Сердцевиной процесса подготовки журналиста такого класса является формирование у него социологического мышления.

Мышление - это анализ, синтез и обобщение, которые включают в себя порождение и динамику смыслов, целей, оценок, мотивов, потребностей. Оно всегда развивается как процесс решения задач или разрешения проблемных ситуаций в практической и умственной деятельности человека, это «процесс ориентировки субъекта при решении интеллектуальных задач на мышление» (Гальперин, 1976: 94).

Социологическое мышление в основе своей имеет научное знание, прежде всего, в области социально-философских наук, всей совокупности наук, изучающих процесс управления, характеризуется объективностью, адекватным отражением социальной реальности, использованием научных методов ее исследования, правдивостью (Коханая, 2016: Электр. ресурс).

Только журналист, обладающий социологическим мышлением, способен эффективно воздействовать на менталитет россиянина, развивать 
в нем черты «маскулинности», помочь осознать значимость демократического стиля управления, его сущность и пробудить желание именно в данном стиле управления, раскрыть значение такой черты менталитета, как «индивидуализм».

Жизненный успех как профессиональное саморазвитие - это, по сути, один из самых значимых современных ресурсов социальной модернизации, особенно, если профессиональное саморазвитие не противоречит существующим в обществе морали и праву.

Перспективы социальной модернизации в российском обществе, несомненно, связаны с кратко рассмотренными выше ее духовными основаниями. Теоретический анализ, результаты эмпирических социологических исследований духовных основ социальной модернизации в России помогут более адекватно понять и разрешить определенные модернизационные противоречия, которые имеют место в нашей стране, а может быть, и ответить на вопрос: почему человек сопротивляется инновациям. Системная модернизация российского общества невозможна без должного учета особенностей менталитета, в том числе и в его социологическом контексте, без активного участия в этом процессе СМК.

Без преувеличения можно утверждать, что ключевая роль социальной модернизации российского общества объективно необходимой трансформации менталитета россиянина принадлежит СМК, которая выполнима только тогда, когда журналист обладает социологическим мышлением и с научных позиций, используя научные методы, исследует социальные факты и социальные процессы. В этом случае журналисты и СМК способствуют интеграции общества, его гуманизации, интеллектуализации, подлинной демократизации, развитию патриотизма.

\section{СПИСОК ЛИТЕРАТУРЫ}

Аникин, В. А. (2009) Работа в повседневной жизни россиян // Социологические исследования. № 12. С. 48-55.

Вознесенская, Е. Д. (2008) Человеческий капитал и проблемы социальных неравенств // Социальные неравенства и социальная политика в современной России / отв. ред. М. К. Горшков, Н. Е. Тихонова. М. : Наука. 423с.

Гальперин, П. Я. (1976) Введение в психологию. М. : Книжный дом «Ниверситет». 152 с.

Горшков, М. А. (2010) Социальные факторы модернизации российского общества с позиций социологической науки // Социологические исследования. № 12 . С. 28-41.

Ильинский, И. М. (2006) Образование. Молодежь. Человек. М. : Изд-во МосГУ.

Кастельс, М. (2000) Информационная эпоха. Экономика, общество и 
культура / пер. с англ. под науч. ред. О. И. Шкаратана. М. : ГУ ВШЭ. 606 с.

Коновченко, С. В., Киселев, А. Г. (2004) Информационная политика в России. М. : РАГС. 528 с.

Коханая, О. Е. (2016) Профессиональные журналистские дисциплины в системе современного университетского образования [Электронный ресурс] // Научные труды Московского гуманитарного университета. № 1. URL: http://journals.mosgu.ru/trudy/article/view/203 (дата обращения: 10.06.2016). DOI: http://dx.doi.org/10.17805/trudy.2016.1.8

Hofstede, G. (1980) Culture's Consequences: International Differences in Work-Related Values. CA: SAGE. 327 p.

Hofstede, G. (2001) Culture's Consequences: Comparing Values, Behaviors, Institutions and Organizations Across Nations. CA: SAGE. 596 p.

Акимова Елена Михайловна - кандидат исторических наук, доцент кафедры социологии Московского гуманитарного университета. Адрес: 111395, Россия, г. Москва, ул. Юности, д. 5. Тел.: +7 (495) 302-01-36. Эл. адрес: e.m.akimova@yandex.ru

Akimova Elena Mikhaylovna, Candidate of History, Associate Profes-sor, Department of Sociology department, Moscow University for the Humanities. Postal address: 5 Yunosti St., 111395 Moscow, Russian Federation. Tel.: +7 (495) 302-01-36. E-mail: e.m.akimova@yandex.ru 